\title{
Early Vocabulary Development in Rural and Urban Mozambique
}

\author{
Paul Vogt, ${ }^{1}$ J. Douglas Mastin, ${ }^{2}$ and Suzanne Aussems ${ }^{3}$ \\ ${ }^{1}$ Tilburg Centre for Cognition and Communication, Tilburg University, P.O. Box 90153, 5000 LE Tilburg, Netherlands \\ ${ }^{2}$ Stanford University Developmental Psychology, Language Learning Lab, 50 Serra Mall, Margaret Jacks Building, \\ Stanford, CA 94305, USA \\ ${ }^{3}$ Department of Psychology, University of Warwick, University Road, Coventry CV4 7AL, UK
}

Correspondence should be addressed to Paul Vogt; p.a.vogt@uvt.nl

Received 31 July 2015; Revised 12 October 2015; Accepted 10 November 2015

Academic Editor: Magdalena Janus

Copyright (C) 2015 Paul Vogt et al. This is an open access article distributed under the Creative Commons Attribution License, which permits unrestricted use, distribution, and reproduction in any medium, provided the original work is properly cited.

\begin{abstract}
This paper presents an adaptation of the MacArthur-Bates Communicative Development Inventories (short version) into three languages spoken in Southern Mozambique. The tool was adapted to study vocabulary development among children of 12 to 25 months of age in two communities: a rural, monolingual Changana speaking community and an urban bilingual Ronga and Portuguese speaking community. We present a norming study carried out with the adaptation, as well as a validation study. The norming study revealed various predictors for reported expressive and receptive vocabulary size. These predictors include age, socioeconomic status, reported health problems, caregiving practices, and location. The validation of the CDI among a small sample in both communities shows positive correlations between the reported expressive vocabulary scores and children's recorded word production. We conclude that the adapted CDI is useful for research purposes and could be used as a template for adaptations into other languages from similar cultures.
\end{abstract}

\section{Introduction}

The MacArthur-Bates Communicative Development Inventories [1] are standardized parent report forms to assess the vocabulary development of children between 8 and 37 months of age [2-5]. According to a recent survey, the CDIs have been adapted into at least 68 languages of which the vast majority relate to languages spoken in industrialized communities [6]. Of the reported 68 adaptations, only 15 relate to languages spoken in nonindustrial countries, of which 7 are from languages spoken in sub-Saharan Africa [7]. Moreover, while CDIs developed for industrialized communities are normed and used in various large-scale research projects, CDIs developed for nonindustrialized communities are often used in small-scale studies and therefore not normed [8].

This paper presents a novel adaptation of the CDI short version [9] into three languages spoken in Mozambique: Changana, Ronga, and (Mozambican) Portuguese. The adaptation was designed for the purpose of a study on the cultural and social aspects of language acquisition in a rural monolingual Changana speaking community and an urban, bilingual Ronga and Portuguese speaking community [1012]. Changana and Ronga are mutually intelligible Southern Bantu languages within the Tsonga language group, which is also spoken in parts of South Africa [13, 14]. Portuguese is Mozambique's official language and is widely spoken in urban areas and governmental institutes, and it is the official language used in schools.

To allow for a reliable comparison of vocabulary development between the rural and urban communities, a norming study and validation study were carried out in both communities. The main goal of this paper is to present the adapted CDI as an instrument to measure vocabulary development in these three languages and as a useful source for future adaptations into other languages spoken in related African cultures.

(1) Adapting the CDI. Registered short versions of the CDIs have been developed for approximately 20 languages [6]. Typically these adaptations are developed for languages spoken in large industrialized communities, such as Cantonese and Mandarin [15], American English [9], German [16], Mexican Spanish [5], and Swedish [17]. There also exist a few short 
forms for African languages, such as Chichewa/Nyanja and Chiyao from Malawi [18] and Kiswahili and Kigiriami from Kenya and other countries [19]. Usually when short forms of CDIs are developed, they are distilled from the long versions $[5,9,19]$. However, when long versions are not available and when the cost to develop a long version is too high (e.g., because only few people speak the language or part of the community is illiterate), it may be better to develop short forms from the start. This was done for Chichewa and Chiyao [18], which were adapted directly from the short versions developed for Kenya [7].

As there were no other (short) versions of CDIs for Mozambican or other African languages available at the start of this project, we adapted the American English CDI short form [9] into our target languages. When using an instrument developed for a culture different than the culture under study, one cannot simply translate the instrument but must carefully adapt it to make it appropriate for the target culture [20]. Rather than adapting the CDI based on frequency lists derived from transcripts of child speech as is common practice in adapting the CDI $[19,21]$, we relied on the results obtained from parental interviews, consultations with field workers, and a few rounds of piloting and readapting the tool. Moreover, rather than adapting a different CDI for each community, we decided to first construct one culturally broad adaptation for the Mozambican culture in Portuguese that could be used in both communities by translating the items from this adaptation into the specific languages spoken in these communities. Designing one conceptual adaptation for such similar communities and translating these into the specific languages spoken are an acceptable alternative, provided one bears in mind that such instruments could be very sensitive to linguistic or cultural differences [7, 22].

In most-if not all-African countries, several languages are commonly spoken or considered official. For instance, about 23 different languages are spoken in Mozambique alone, and most are Bantu languages [14]. Most sub-Saharan African countries have similar language diversity. Developing an instrument, such as the CDI, to measure vocabulary development using a separate adaptation for each language would be very costly, especially when norms have to be developed for each language. One objective of the current research is to explore the potential of using a top-down approach: creating one conceptual adaptation for two different learning environments with different languages.

One challenge is to adapt a CDI for multilingual communities, which are omnipresent in urban communities in Africa. Especially for these communities, the focus on one conceptual adaptation is crucial. Bilingual language learners tend to differ in vocabulary development of the individual languages when compared to the vocabulary development of monolingual speakers. However, when total conceptual vocabulary is measured by counting the number of items that the child produces or comprehends in either or both languages, children in bilingual environments develop language skills similarly to monolingual children $[23,24]$.

(2) Culture and SES. In our norming study, we test for possible effects of a variety of demographic factors on the expressive and receptive vocabulary development of children from rural and urban Mozambique. These two cultural communities fit well within the classification of learning environments proposed by Greenfield [25] and Keller [26]. Many differences between these two communities can be characterized in terms of sociodemographic factors and the adopted lifestyles. The lifestyle of the rural community tends to focus on subsistence farming, and rural communities are often smaller, poorer, less well educated, and more focused on the community than urban communities. In subsistencebased farming communities, parents often expect children to help in daily activities from an early age onward, so caregiving focuses on children acquiring such skills by stimulating their motor development, but not necessarily their language development. On the other hand, urban communities have adopted a market-based lifestyle and tend to be larger, more well educated, more individualized, and more driven towards cognitive development than rural communities. In urban communities, parents tend to expect children to receive formal education and perform well in school. To facilitate this, caregivers in urban communities tend to foster language learning and cognitive development.

Differences in socioeconomic status (SES) have been found to be good predictors for vocabulary development and have been associated with differences in the style of parenting $[4,27,28]$. In particular, children from lower SES families tend to be talked to less frequently, receive relatively little encouragement in cognitive development, and are more frequently addressed in a negative voice [27]. Similar findings were observed in studies comparing rural and urban Mozambique with the Netherlands; in rural Mozambique, the number of child-directed utterances is about five times less than in urban Mozambique, which in turn is about half the amount of child-directed utterances that Dutch children receive [12]. Moreover, about 50\% of the child-directed feedback had a negative voice in the rural Mozambican community, as opposed to $31 \%$ in urban Mozambique and only $5 \%$ in the Netherlands. Similar high levels of negative voice were also observed among the Gusii from Kenya [29].

In addition to differences in learning environments and SES, there are other factors that were shown to influence vocabulary development. For instance, gender [30] and children's reported health problems $[31,32]$ can have a strong effect on their vocabulary development. Also, it may well be that having multiple caregivers can have an effect on vocabulary development [33]. In our norming study, we have collected information about these demographic factors in order to assess their possible influence on vocabulary development in rural and urban Mozambique.

In the remainder of this paper, we explain our methods for adapting the CDI short forms, collecting scores, and norming the data, as well as for validating the CDI with measures from children's speech recordings. We then present the results of the validation and the norming study, including analyses of demographic factors on reported vocabulary size. Finally, all findings are discussed in the context of further use of the adaptation for research purposes. 


\section{Materials and Methods}

In this section we first report how we adapted the CDI for Mozambique and then explain the procedures and analyses for our norming study. Finally, we explain how we validated the CDI with spontaneous speech recordings of a small sample of children who participated in our longitudinal study and did not take part in the norming study.

2.1. CDI Adaptation for Mozambique. Our starting point for the CDI adaptation was an original list of 113 words, consisting of the entire CDI Short Form I ( 89 words) and part of the CDI Short Form II (A and B) (24 words) [9]. Words from Form II were added in order to create one word list that was applicable to children up to the age of 25 months, which coincides with the age range of our longitudinal field studies [11, 12]. This expansion was necessary, because Form I was designed for children between 8 and 18 months, whereas Form II was designed for children between 16 and 30 months. We chose to compile a short list rather than a long list, because the CDI had to be administered through face-toface interviews, due to the high level of illiteracy within the communities. Instead of adapting the CDI for the three different languages separately, we initially constructed one culturally broad adaptation of the list into Portuguese. After a first pilot of this list, it was translated into Changana and Ronga with the help of local research assistants. Translations were confirmed, when possible, with a Ronga-Portuguese dictionary [34].

For the adaptation, we carefully considered whether the 113 items on the original, English list were culturally appropriate for Mozambican communities and had a suitable translation into the target languages. We identified 38 conceptual items that were not and replaced these with items that were considered more appropriate for the culture, lifestyle, and environment of Mozambican families. All replaced words fulfilled the syntactic-semantic properties of the original item. Examples of items that we replaced include goat for duck, ox for lion, cellphone for television, and bring for help. Reasons for replacing these items are that goats are more common than ducks, and most Mozambican children have encountered neither lions nor a television. Moreover, the translation provided by the local informants for help did not convey the same meaning as it does in English, and is also not a word that is commonly used in Changana/Ronga (at least not in the presence of or by children). We therefore changed the word to bring, keeping it within the same syntactic category, and bring is also a prominent word in child-directed speech. During the adaptation, we tried to consider items that would be used in both communities, and when a certain word was more likely to be used in the urban community (e.g., rat), we counterbalanced this by including a word that was more likely to be used in the rural community (e.g., ox).

The resulting adaptations were tested with local informants from both communities, and where necessary we adapted items or improved translations such that they fit better with the responses. We iterated this piloting process twice in each community before the list was considered complete and culturally sound. Nearly all items were reported to be used in the speech addressed to children. The only two items that were not reported to be used in either community were heaven and think. We decided to keep these as a control item to ascertain that these items did not yield a response, especially not for younger children. During the data collection, we noticed that some research assistants did not ask certain items either in a consistent way or in the way intended or that some respondents were not able to separate the word from the action. We therefore removed five additional items from the list: three vocalizations (behehsound of a goat-ouch, and uh-oh) and two words (patty cake and laugh) that were regularly confused with the action they refer to. The final adaptation contains 108 culturally appropriate words (see Appendix).

2.2. Norming Study. Our adapted CDI was normed based on a large sample of rural and urban Mozambican caregivers who were interviewed by local research assistants to administer the CDI. Three adjacent villages near the small town of Chokwe in the Gaza province were selected as the rural field site; and two neighboring, bilingual suburbs of the Maputo capital made up the urban site. These two locations are about $225 \mathrm{~km}$ (140 miles) apart by road. The norming procedure was carried out by including demographic factors and the reported expressive and receptive vocabulary scores in a hierarchical regression analysis.

2.2.1. Participants. Local research assistants were instructed to administer the CDI through face-to-face interviews with primary caregivers of children between 12 and 25 months of age within the two communities. A total of 724 mothers were interviewed. At the time of data collection a response rate was considered too difficult to assess, because our assistants approached mothers in the streets or the markets or went to their houses directly. A total of 87 responses were removed, yielding a total of 637 respondents. A further 71 forms were removed because of missing items on the word list, incomplete demographic information, children's age being outside the target range, or primary languages being different from the three target languages. An additional 16 forms were removed because these contained extreme outliers (exceptionally high scores on reported expressive vocabulary for the youngest children).

2.2.2. Demographic Information. Table 1 shows the demographic information of the 637 participants included in the norming study. The sample contained 378 children from the rural community (mean age $=18.71$ months, 194 females) and 259 from the urban community (mean age $=18.49$ months, 137 females). Families in the rural area $(M=8.10, \mathrm{SD}=3.80)$ had significantly more household members than families in the urban area $(M=6.88, \mathrm{SD}=2.73), t(634)=4.72$, $p<.001$, and the households in the rural area included significantly more children $(M=3.47, \mathrm{SD}=1.59)$ than households in the urban area $(M=2.29, \mathrm{SD}=1.13), t(634)=10.87$, $p<.001$. Maternal education was divided into 6 different categories: none, first part of primary school (EP1) for five years, second part of primary school (EP2) for two years, first 
TABLE 1: Demographic information about the respondents included in our norming study $(N=637)$. Data are split up between the rural $(N=378)$ and urban communities $(N=259)$.

\begin{tabular}{|c|c|c|c|c|c|c|}
\hline & \multicolumn{2}{|c|}{ All } & \multicolumn{2}{|c|}{ Rural } & \multicolumn{2}{|c|}{ Urban } \\
\hline & Mean/N & $(\mathrm{SD} / \%)$ & Mean/N & $(\mathrm{SD} / \%)$ & Mean $/ N$ & $(\mathrm{SD} / \%)$ \\
\hline \multicolumn{7}{|c|}{ General demographic information } \\
\hline Children's age in months & 18.62 & $(4.10)$ & 18.71 & $(3.92)$ & 18.49 & $(4.35)$ \\
\hline Number of females & 331 & $(51.96)$ & 194 & $(51.32)$ & 137 & $(52.90)$ \\
\hline Number of males & 306 & $(48.04)$ & 184 & $(48.68)$ & 122 & $(47.10)$ \\
\hline Health problems & 236 & $(37.05)$ & 200 & $(52.91)$ & 36 & $(13.90)$ \\
\hline Individuals per household & 7.60 & $(3.46)$ & 8.10 & $(3.80)$ & 6.88 & $(2.73)$ \\
\hline Children per household & 2.99 & $(1.53)$ & 3.47 & $(1.59)$ & 2.29 & $(1.13)$ \\
\hline \multicolumn{7}{|l|}{ Maternal education } \\
\hline None & 108 & $(16.95)$ & 96 & $(25.40)$ & 12 & $(4.63)$ \\
\hline Primary school & 464 & $(72.84)$ & 261 & $(69.05)$ & 203 & $(78.38)$ \\
\hline Higher & 65 & $(10.20)$ & 21 & $(5.56)$ & 44 & $(16.99)$ \\
\hline \multicolumn{7}{|l|}{ Secondary caregiver } \\
\hline None & 160 & $(25.12)$ & 48 & $(12.70)$ & 112 & $(43.24)$ \\
\hline Sibling & 174 & $(27.31)$ & 152 & $(40.21)$ & 22 & $(8.49)$ \\
\hline Adult & 303 & $(47.57)$ & 178 & $(47.09)$ & 125 & $(48.26)$ \\
\hline \multicolumn{7}{|l|}{ First language } \\
\hline Ronga & 8 & $(1.26)$ & 0 & $(0.00)$ & 8 & $(3.09)$ \\
\hline Changana & 447 & $(70.17)$ & 377 & (99.74) & 70 & $(27.03)$ \\
\hline Portuguese & 182 & $(28.57)$ & 1 & $(0.26)$ & 181 & $(69.88)$ \\
\hline \multicolumn{7}{|l|}{ Second language } \\
\hline Ronga & 28 & $(4.40)$ & 0 & $(0.00)$ & 28 & $(10.81)$ \\
\hline Changana & 138 & $(26.66)$ & 1 & $(0.26)$ & 137 & $(52.90)$ \\
\hline Portuguese & 134 & $(21.04)$ & 54 & $(14.29)$ & 80 & $(30.88)$ \\
\hline Other Bantu language(s) & 29 & $(4.55)$ & 17 & $(4.50)$ & 12 & $(4.63)$ \\
\hline English & 3 & $(0.47)$ & 2 & $(0.77)$ & 1 & $(0.26)$ \\
\hline None & 324 & $(50.86)$ & 317 & $(83.86)$ & 7 & $(2.70)$ \\
\hline
\end{tabular}

Note. The sum of the percentages of the second language slightly exceeds $100 \%$, because a number of respondents reported two other languages next to the first language.

part of secondary school (ESG1) for three years, second part of secondary school (ESG2) for two years, and higher education. For our analysis, we collapsed these into three categories: 108 mothers (17\%) received no education, 464 mothers (73\%) completed EP1 or EP1 and EP2, and 65 mothers (10\%) obtained further education. Education categories were collapsed in this manner for two reasons: first, to represent milestones in major education accomplishments; and second, to reduce the number of predictors for our regression analysis. Distributions between the rural and urban communities show that mothers from the rural area more often received no education than mothers from the urban area. On the other hand, mothers from the urban area more often received further education than mothers from the rural area.

We asked respondents whether they had experienced any health-related problems with their child, as poor health could negatively affect language development. In particular, we asked whether there were any problems during pregnancy, whether the child was born prematurely, whether the child had any problems with vision or with hearing, and whether the child had been hospitalized or seriously ill for a prolonged period of time. Hearing problems were reported for
75 children; typically these were ear infections. Since the reported scores on expressive and receptive vocabularies for these children did not differ significantly from the rest of the sample; these children were included in our analysis. In total, $236(37 \%)$ respondents answered at least one of these questions affirmatively, 200 of whom were from the rural community.

As sibling caregiving is a prominent feature of African caregiving practices and may negatively affect language development [33], we asked mothers whom they considered to be the secondary caregiver of their child. In total, 160 (25\%) respondents indicated they were the sole caregiver, 174 (27\%) mentioned a sibling, and 303 (48\%) mentioned another adult, such as grandmother, father, or aunt. There is a clear difference between rural and urban caregiving; where $40 \%$ of the rural children were reported to have a sibling as secondary caregiver, no secondary caregiver was reported for $43 \%$ of the urban children.

Table 1 summarizes occurrence and frequency of languages spoken in the households. The vast majority of urban respondents $(70 \%)$ reported Portuguese as the first language followed by Changana (27\%) and then Ronga (3\%). In the 
rural community, all but one caregiver reported Changana as the first language. In $97 \%$ of the urban households caregivers reported to speak more than one language. Typically the second language was either Changana, Portuguese, or Ronga, but sometimes it was another Bantu language or English. In six cases, a third language was reported. In 16\% of the rural households a second (or third) language is spoken. If that was the case, it was most often Portuguese, but also other Bantu languages and English were occasionally reported.

2.2.3. Data Collection Procedure. We trained five local research assistants (three urban and two rural) to administer the CDIs with primary caregivers. All research assistants had finished secondary school and were bilingual speakers of Portuguese and Changana or Ronga in which they were literate. At the start of this training, we explained the purpose and procedure of administering the CDI, as outlined below. After a few rounds of practice, the research assistants administered the CDIs during the first data collection periods of our longitudinal study under direct supervision of the first two authors. Occasionally, the research assistants were corrected during the process or received feedback on how to improve their interviewing techniques.

After this period of training, the research assistants independently administered the CDI by means of face-to-face interviews with primary caregivers of children aged between 12 and 25 months. During the interviews, the assistants first asked for the date of birth of the child to confirm that he or she was within the appropriate age range. Next, the above reported demographic questions were asked, after which the assistants asked for each lexical item on the list whether the child could produce the word and, if not, whether the child could comprehend the word. If the child also could not comprehend the word, a box labeled neither was ticked to ascertain all items were asked. At the end of the interview, the caregiver was asked to sign the form, so we could verify that the assistants had indeed interviewed different respondents (illiterate participants could sign by placing an "X").

In the urban community, research assistants were trained to continuously remind the respondents that we were interested to know whether the child can produce or comprehend each word in either Portuguese or Ronga, thus allowing us to measure total conceptual vocabulary of bilinguals [23, 24]. We initially instructed the research assistants to mark for each word in which language the item was known, but soon this turned out to be infeasible. So, we have no information regarding the proportions of words in each of the two languages but only whether the child can say or understand the conceptual item in at least one of the languages. In the monolingual rural community, the assistants administered the word list in Changana.

The data collection lasted approximately four weeks, and, at the end of each week, the forms were inspected by the first two authors, who verified whether the children were in the appropriate age range, whether all items were marked, and whether the forms were signed by the primary caregivers. The assistants were paid a small fee for each CDI that fulfilled these requirements.
2.2.4. Data Analysis. Our dependent variables were reported expressive vocabulary size and reported receptive vocabulary size. The data were organized in the age per month. For analyses, we first computed the expressive and receptive vocabulary scores of each child as the total number of items children were reported to speak or understand divided by the total number of items that were on the list. Using these scores, hierarchical logistic regression analyses were carried out with various demographic variables as predictors. The reason for doing logistic regression analyses is that the scores over time show a logistic growth rather than a linear trend as is common with CDI scores $[1,15]$.

We started each hierarchical regression by inserting age as the main predictor. Second, we inserted gender and maternal education, as these are factors that are known to contribute to children's vocabulary development [27]. Third, we inserted location, health problems, or secondary caregiver as predictors. We applied these different predictors in all possible combinations in the hierarchical regression to explore whether these factors could explain part of the observed variance in reported CDI scores (for expressive as well as receptive vocabulary). We also inserted other variables, such as household size or birth other, but these did not explain any variance significantly. We only report those variables that can explain part of the observed variance.

2.3. Validation Study. The CDI was validated based on a small sample of rural and urban children who participated in our longitudinal study to investigate the relation between multimodal interactions and vocabulary development [11, 12]. The validation was carried out by correlating the type frequencies of children's speech with their reported CDI scores for expressive vocabulary.

2.3.1. Participants. From each community, 14 children were recruited, resulting in 28 participants (12 girls). None of these participants took part in the norming study. The demographic and language differences reflect those of the norming sample (for more details, consult [11, 12]). In the urban community, all caregivers reported either Changana or Portuguese as the first language spoken in the house, and all rural caregivers reported Changana as the first language. Children were recorded using a video camera and microphone at 13 , 18 , and 25 months of age. Prior to the study, the local research assistants explained the general purpose and procedures of the study to the families in their native language. They were informed that their participation was voluntary, would not cause them any harm, or provide any direct benefits and that they could withdraw from the study at any time for any reason. Informed written consent was obtained.

2.3.2. Procedure. The children were recorded twice at each age. The first recording was used to accommodate the children and their families to our presence and procedures. The second recording was used for data analysis. All recordings were carried out at the participants' houses and all adults present were instructed to continue their daily activities and ignore our presence as much as possible. The recordings for 
data analysis ranged from 45 to 75 minutes to ensure there was enough material to transcribe approximately 30 minutes of their verbal behavior.

After these second recordings, the mothers were interviewed to administer the CDI. The procedure for the interviews was the same as described for the norming study. The only difference was that one of the first two authors was present during the interviews and occasionally interrupted the interview to ask for clarification or to request the research assistant to probe the interviewee for verifying their answer.

2.3.3. Data Analysis. Of each video, 30 minutes were selected in which the child was clearly visible on camera, not interacting extensively with the researchers, and not being breastfed for more than two minutes. Local research assistants transcribed the child speech of these 30-minute fragments under continuous direct supervision of one of the first two authors. All intelligible speech was first transcribed in the language spoken, and where necessary, this was translated into Portuguese. All unintelligible speech and vocalizations, such as uhm, laughter, and cries, were marked but not included in the present analysis. For each video, we counted the number of different word types the children produced. Words were considered different if they had completely different meanings. Words that were similar (e.g., "mama" and "ma" for mother, "avo" and "vovo" for grandmother, "keke" and "makeke" for biscuit, or "nila" and "nilava" for "I want") were counted as one. Also words with relatively complex morphology, such as "nitakuba" ("ni"-I, "ta"-will, "kuba"-hit, Ø-you), were counted as one, because it is unclear whether the children learned the morphology of the word or whether it was stored as a holophrase.

The number of different word types recorded in the rural and urban area were collapsed for further analysis. The number of different word types measured at the three age groups were then correlated with the reported expressive vocabulary measured by the CDI at these three age groups. We computed Spearman rank correlations, because the speech data in this small sample revealed a skewed distribution.

\section{Results}

3.1. Validation Findings. The type frequencies revealed a clear increase of expressive vocabulary size from 13 months $(M d n=2)$ to 18 months $(M d n=4)$ to 25 months $(M d n=$ 24) in both communities. The same holds for the reported CDI scores on expressive vocabulary: $M d n=5$ at 13 months, $M d n=19.5$ at 18 months, and $M d n=68$ at 25 months. The correlations yielded $r(28)=0.50, r(28)=0.55$, and $r(27)=$ 0.50 (all $p<.01$ ) for 13, 18, and 25 months, respectively. Note that type frequencies for one participant at 25 months were missing, so here $n=27$. Given that these are Spearman correlations, the results demonstrate that the parental reports of children's expressive vocabulary using our CDI adaptation correspond well with the rank of their child's proficiency in terms of the number of different words they produced in half an hour of spontaneous speech on the same day that the CDI was administered.

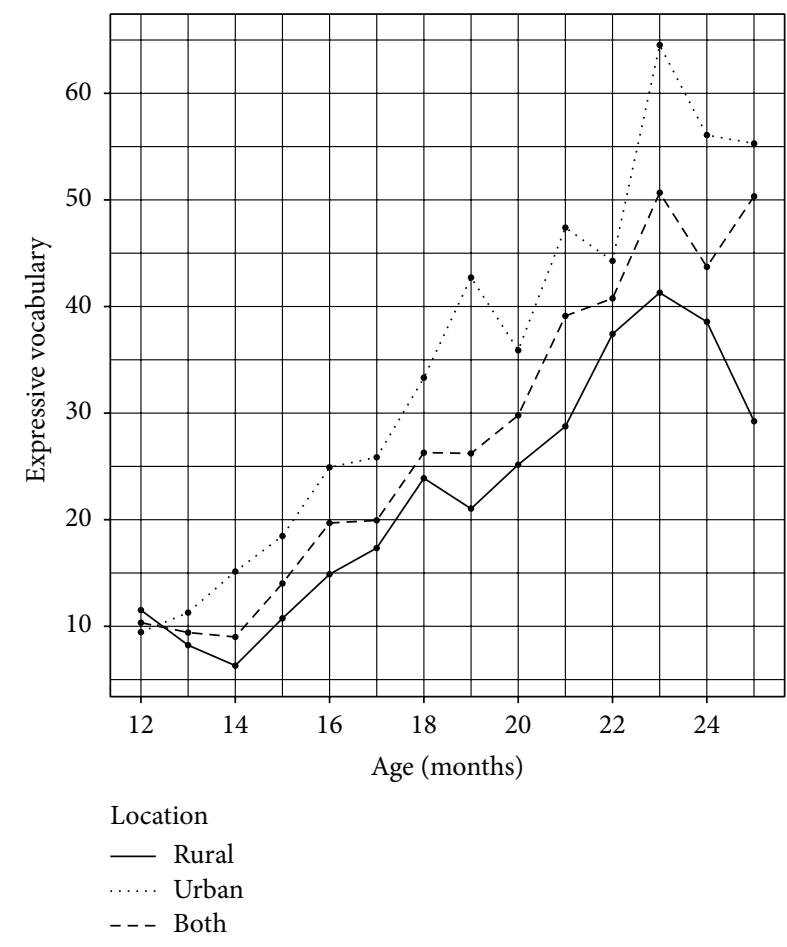

FIGURE 1: Expressive vocabulary size measured in number of words ( $y$-axis) per age group ( $x$-axis). The dashed line in the middle shows the scores of all respondents combined, the dotted line at the top those from the urban community, and the solid line at the bottom those from the rural community.

3.2. Expressive Vocabulary. We now move from the validation study to the norming study. Figure 1 shows the average scores on expressive vocabulary per month in the two communities separately and combined. For the combined data, the average score for expressive vocabulary is 10 words at 12 months and increases steadily from 14 months onward to approximately 50 words at 23 months. At 24 months, the average score is slightly lower, but at 25 months it returns to 50 words, suggesting that the CDI list may have a ceiling effect for older children. The scores obtained on expressive vocabulary in the urban community are clearly higher than in the rural community. In the rural community, the scores drop drastically at 25 months, but this can be explained by a very small sample $(n=3)$ in this age group.

To assess which demographic factors contributed to the reported development, a hierarchical logistic regression was carried out (Table 2). Step 1 shows that the children's age in months was a significant predictor of expressive vocabulary size $-\beta=0.18, t(636)=18.33, p<.001-$ and could explain $41.6 \%$ of the variance (Nagelkerke $R^{2}$ ). The odds-ratio indicated an average increase in expressive vocabulary of $19 \%$ per month.

Step 2 shows that gender significantly predicted expressive vocabulary scores $-\beta=0.13, t(636)=2.50, p=$ .013 -explaining $3.5 \%$ of the variance, and the odds-ratio indicated that girls produced $14 \%$ more words than boys. 
TABLE 2: Results of a hierarchical logistic regression analysis for expressive vocabulary.

\begin{tabular}{|c|c|c|c|c|c|}
\hline & \multirow{2}{*}{$\beta$} & \multirow{2}{*}{$\operatorname{SE} \beta$} & \multirow{2}{*}{ OR } & \multicolumn{2}{|c|}{ 95\% CI OR } \\
\hline & & & & Lower & Upper \\
\hline \multicolumn{6}{|l|}{ Step $1\left(R^{2}=.416\right)$} \\
\hline (Intercept) & $-4.44^{* * *}$ & 0.20 & & & \\
\hline Age in months & $0.18^{* * *}$ & 0.01 & 1.19 & 1.17 & 1.22 \\
\hline \multicolumn{6}{|l|}{ Step $2\left(\Delta R^{2}=.032\right)$} \\
\hline Gender & $0.13^{*}$ & 0.05 & 1.14 & 1.04 & 1.27 \\
\hline $\begin{array}{l}\text { Mother's education } \\
\text { (Low) }\end{array}$ & $-0.18^{+}$ & 0.10 & 0.84 & 0.69 & 1.01 \\
\hline $\begin{array}{l}\text { Mother's education } \\
\text { (High) }\end{array}$ & $0.49^{* * *}$ & 0.11 & 1.62 & 1.31 & 2.01 \\
\hline \multicolumn{6}{|l|}{ Step $3.1\left(\Delta R^{2}=.047\right)$} \\
\hline $\begin{array}{l}\text { Location (rural or } \\
\text { urban) }\end{array}$ & $0.53^{* * *}$ & 0.07 & 1.69 & 1.47 & 1.95 \\
\hline \multicolumn{6}{|l|}{ Step $3.2\left(\Delta R^{2}=.011\right)$} \\
\hline $\begin{array}{l}\text { Reported health } \\
\text { problems }\end{array}$ & $-0.18^{* * *}$ & 0.05 & 0.84 & 0.75 & 0.93 \\
\hline \multicolumn{6}{|l|}{ Step $3.3\left(\Delta R^{2}=.004\right)$} \\
\hline $\begin{array}{l}\text { Secondary caregiver } \\
\text { (sibling) }\end{array}$ & $-0.20^{*}$ & 0.10 & 0.82 & 0.67 & 1.00 \\
\hline $\begin{array}{l}\text { Secondary caregiver } \\
\text { (adult) }\end{array}$ & -0.06 & 0.09 & 0.94 & 0.79 & 1.11 \\
\hline Test (Model 3.1) & & & $\chi^{2}$ & $p$ & $\mathrm{df}$ \\
\hline Wald's statistic & & & 409.9 & 0.0 & 4 \\
\hline Goodness-of-fit & & & 67.04 & 0.0 & 5 \\
\hline
\end{tabular}

Note. ${ }^{+} p<0.1 ;{ }^{*} p<0.05 ;{ }^{* *} p<0.01 ;{ }^{* * *} p<0.001$.

Children whose mothers did not receive any formal education scored slightly lower on expressive vocabulary than those whose mothers had completed at least one level of primary education, but this result did not reach significance $-\beta=$ $-0.18, t(636)=-1.84, p=.066$. Children whose mothers received both primary and secondary education, on the other hand, produced significantly more words than children whose mothers received only primary education$\beta=0.49, t(636)=4.41, p<.001$. The odds-ratio indicated that children of mothers who received primary and secondary education on average produced $62 \%$ more words than children of mothers who received only primary education. The addition of maternal education to the regression model explained $2.6 \%$ of the variance. Figure 2 shows that differences in expressive vocabulary become larger as age increases.

At Step 3, we entered location, reported health problems, or secondary caregiver as a predictor in three separate models. We found that location was the strongest predictor$\beta=0.53, t(636)=7.32, p<.001$ - which explained $4.7 \%$ of the variance. Children raised in the urban community produced 69\% more words than children raised in the rural community. A reported health problem was a negative predictor of vocabulary growth $-\beta=-0.18, t(636)=-3.41$, $p<.001-$ and explained $1.1 \%$ of the variance. The oddsratio indicated that children who had experienced health problems prior to the CDI administration produced $16 \%$ less words than children without reported health problems (Figure 2). Location and reported health problems were significant predictors of expressive vocabulary when entered in separate models, but not when combined in the same model. The reason for this is that both variables were strongly associated with each other: $\chi^{2}(1)=98.62, p<.001$. Health problems were more often reported in the rural community than in the urban community (cf. Table 1).

Having a sibling as a secondary caregiver negatively influenced expressive vocabulary size $-\beta=-0.20, t(636)=$ $-1.98, p=.048$. The odds-ratio revealed that children with siblings as secondary caregivers produced $18 \%$ less words than children who were reported to have a primary caregiver only. Having an adult as secondary caregiver did not have a significant effect on expressive vocabulary size. The effect of secondary caregivers is small as it explained only $0.4 \%$ of the variance in expressive vocabulary size. When information about the secondary caregiver was entered in the model together with location, it did not significantly predict expressive vocabulary size. As with reported health problems, having a secondary caregiver is strongly associated with the rural community and less common in the urban community: $\chi^{2}(1)=74.62, p<.001$.

To compare responses to individual items on the list, we carried out a visual inspection of item-by-item responses between both communities. These inspections revealed that ten items showed a floor or ceiling effect (i.e., items that either no or all respondents reported children could produce) in both communities. Since these occurred at both locations, they did not affect our comparison. However, another fifteen items only showed a flooring effect at the rural community. Five of these items turned out to be translations of words used in adult language, but not in the presence of a child, or by children. These five items brought about a small bias, but since the differences between the communities are substantially larger than five items for the older age groups (cf. Figure 1), the influence of these items is negligible. Cultural differences between the two communities may have caused a flooring effect in the rural community for the ten other items. Many of these items have a social function (i.e., words that translate to "goodbye," "to hug," and "them"), which appeared relatively more frequently in the child-directed speech recorded in the urban community than in the rural community [12].

3.3. Receptive Vocabulary. Figure 3 shows the development of receptive vocabulary over time. At 12 months, children comprehended about 45 words from our list, andas for expressive vocabulary-receptive vocabulary increased steadily from 14 months onwards to 80 words at 25 months. Here, we see that the reported receptive vocabulary tends to be larger in the rural community than in the urban community.

The results of a hierarchical logistic regression to predict receptive vocabulary scores with demographic factors are shown in Table 3. Age $-\beta=0.10, t(636)=17.53, p<$ $.001-$ gender $-\beta=0.07, t(636)=2.06, p=.040$ - and location $-\beta=-0.21, t(636)=-4.24, p<.001-$ significantly 


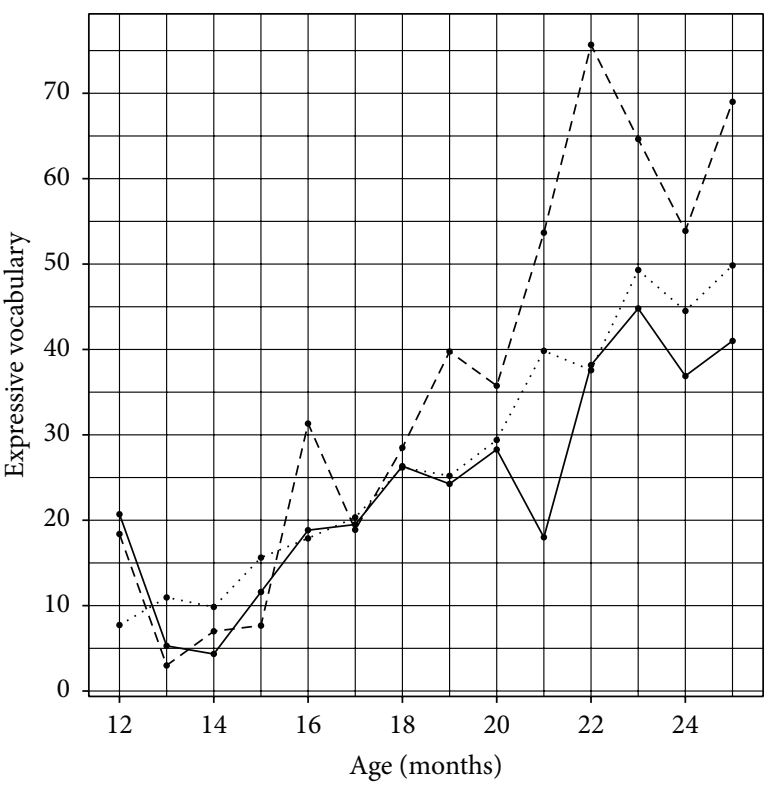

SES

$$
\begin{aligned}
& \text { - Low } \\
& \ldots . . \\
& \text {-- Mid } \\
&
\end{aligned}
$$

(a)

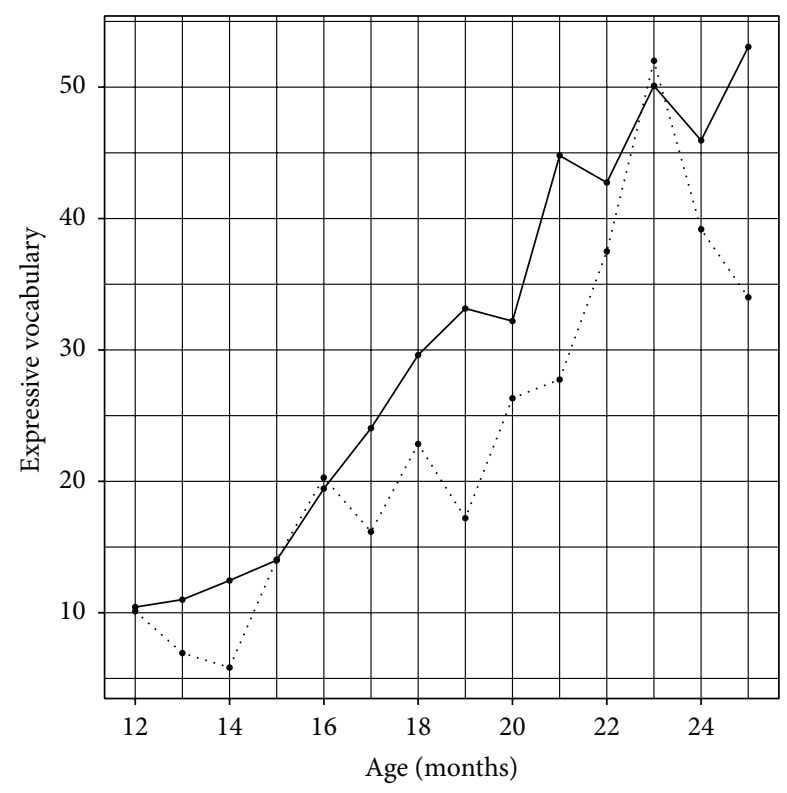

Health problems$$
\text { No }
$$

(b)

FIGURE 2: The average scores on expressive vocabulary per month for the three different levels of SES as measured through maternal education (a) and for children with and without reported health problems (b).

\begin{tabular}{|c|c|c|c|c|c|}
\hline & \multirow{2}{*}{$\beta$} & \multirow{2}{*}{ SE $\beta$} & \multirow{2}{*}{ OR } & \multicolumn{2}{|c|}{$95 \%$ CI OR } \\
\hline & & & & Lower & Upper \\
\hline \multicolumn{6}{|l|}{ Step $1\left(R^{2}=.341\right)$} \\
\hline (Intercept) & $-1.51^{* * *}$ & 0.11 & & & \\
\hline Age in months & $0.10^{* * *}$ & 0.01 & 1.11 & 1.10 & 1.12 \\
\hline \multicolumn{6}{|l|}{ Step $2\left(\Delta R^{2}=.004\right)$} \\
\hline Gender & $0.07^{*}$ & 0.03 & 1.07 & 1.00 & 1.14 \\
\hline \multicolumn{6}{|l|}{ Step $3\left(\Delta R^{2}=.018\right)$} \\
\hline $\begin{array}{l}\text { Location } \\
\text { (rural or urban) }\end{array}$ & $-0.20^{* *}$ & 0.05 & 0.82 & 0.75 & 0.90 \\
\hline \multicolumn{6}{|l|}{ Step $4.1\left(\Delta R^{2}=.016\right)$} \\
\hline $\begin{array}{l}\text { Secondary caregiver } \\
\text { (sibling) }\end{array}$ & $0.23^{* *}$ & 0.07 & 1.26 & 1.10 & 1.44 \\
\hline $\begin{array}{l}\text { Secondary caregiver } \\
\text { (adult) }\end{array}$ & $0.22^{* * *}$ & 0.06 & 1.25 & 1.11 & 1.40 \\
\hline \multicolumn{6}{|l|}{ Step $4.2\left(\Delta R^{2}=.006\right)$} \\
\hline $\begin{array}{l}\text { Reported health } \\
\text { problems }\end{array}$ & $-0.09^{*}$ & 0.04 & 0.91 & 0.85 & 0.98 \\
\hline Test (Model 4.1) & & & $\chi^{2}$ & $p$ & $\mathrm{df}$ \\
\hline Wald's statistic & & & 355.9 & 0.0 & 4 \\
\hline Goodness-of-fit & & & 9.23 & 0.0 & 5 \\
\hline
\end{tabular}

TABLE 3: Results of a hierarchical logistic regression analysis for receptive vocabulary.

Note. ${ }^{*} p<0.01 ;{ }^{* *} p<0.01 ;{ }^{* * *} p<0.001$. predicted receptive vocabulary size. Age explained 34.1\% of the variance in receptive vocabulary size, and the oddsratio showed that per month, children's receptive vocabulary increased by $10 \%$. Gender explained $0.4 \%$ of the variance in receptive vocabulary size, and the odds-ratio indicated that girls comprehended 7\% more words than boys. Location explained $1.8 \%$ of the variance in receptive vocabulary size, and the odds-ratio revealed that urban children comprehended $19 \%$ more words than rural children (Figure 4). SES (or maternal education) was not a significant predictor of receptive vocabulary size.

The fourth step of our hierarchical regression analysis showed that responses regarding secondary caregivers or responses regarding health problems significantly explained some of the variance in receptive vocabulary size.

First, having a secondary caregiver was positively related to children's receptive vocabulary scores. This positive relationship remained regardless of whether this was a sibling$\beta=0.23, t(636)=3.28, p=.001-$ or another adult (i.e., an aunt or a grandmother) $-\beta=0.22, t(636)=3.79, p<.001$; odds-ratios revealed an average increase of $26 \%$ and $25 \%$, respectively, when children had a secondary caregiver (see Figure 4). Having a secondary caregiver explained $1.6 \%$ of the variance.

Second, whether or not children had experienced health problems explained $0.6 \%$ of the variance in the reported receptive vocabulary scores $-\beta=-0.09, t(636)=-2.47$, 


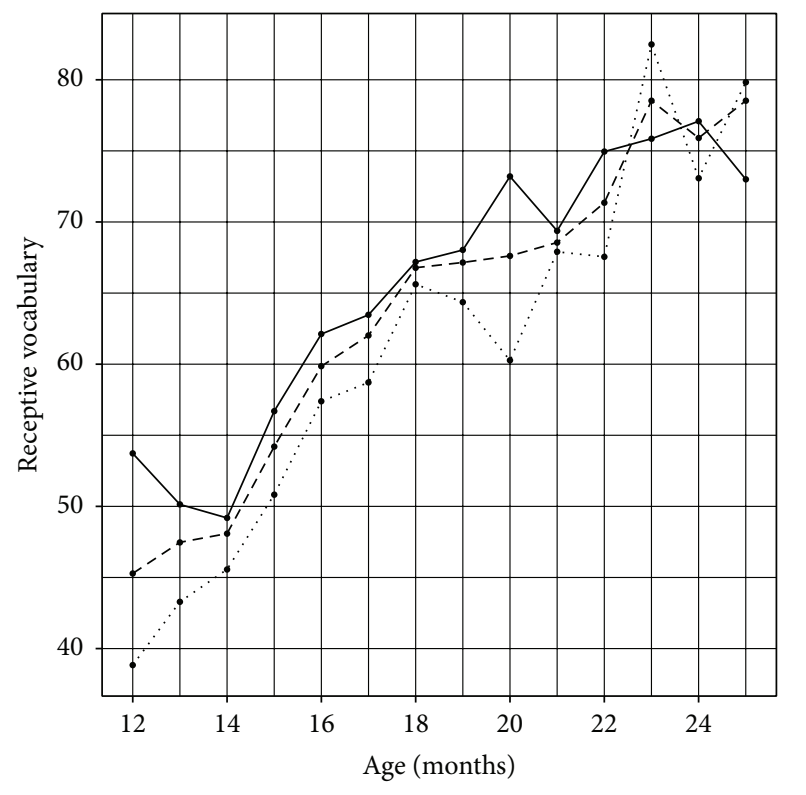

Location

- Rural

..... Urban

- - - Both

FIGURE 3: Receptive vocabulary size measured in number of words ( $y$-axis) per age group ( $x$-axis). The dashed line in the middle shows the scores of all respondents combined, the dotted line at the bottom those from the urban community, and the solid line at the top those from the rural community.

$p=.014$. Children who had experienced health problems prior to the CDI administration comprehended 9\% less words than children who had not experienced any health problems. Having a secondary caregiver and reported health problems both were significant predictors of receptive vocabulary size when entered in separate models, but not when they were entered in the same model. The reason for this is that having a secondary caregiver is significantly associated with reported health problems $-\chi^{2}(1)=4.16, p=.041$ - which is most likely mediated by the fact that they both occur frequently in the rural community, but not in the urban community.

\section{Discussion}

This paper describes the adaptation of the MacArthur-Bates CDIs (short version) [9] into three languages spoken in Southern Mozambique. We present the results of a norming study and a validation study in which this adaptation was successfully used. As many other short CDI versions (e.g., $[5,9]$ ), our adapted list contains 108 items that can be assessed by interviewing primary caregivers of children in the age range of 12 to 25 months. The items were adapted to be culturally appropriate for both rural and urban Mozambique and were translated into Changana for the rural area and Mozambican Portuguese and Ronga for the urban area.

Our validation study of the CDIs for both the rural and urban community indicates that children's reported word production corresponds with the number of different words these children produced during our recordings at 13,18 , and 25 months of age. Given that we reported Spearman rank correlations, these findings suggest that maternal reports at least correspond with the rank of their child's language proficiency. Thus, while mothers still may underestimate or overestimate their child's expressive vocabulary size, they appear to do so in a systematic manner.

To summarize, our norming study revealed that the general trend observed in the development of expressive vocabulary (see Figure 1) is in accordance with observations from CDI studies focusing on other languages $[1,5,15]$, as well as with the developmental trends of children's spontaneous word production [27]. Of the demographic variables we collected, being a female, having a mother with a higher level of education, and living in an urban area were-in addition to age-positively associated with children's expressive vocabulary size. A similar trend was observed for the development of receptive vocabulary (Figure 3), which is also in line with previous studies on vocabulary development $[1,5,15]$. However, mother's education levels did not predict receptive vocabulary size significantly. Having a sibling as a secondary caregiver was negatively associated with expressive vocabulary size, while it had a positive association with receptive vocabulary size. Reported health problems negatively influenced both expressive and receptive vocabulary size. For expressive vocabulary size, maternal education and reported health problems were only significant predictors when they replaced location in the regression analysis; for receptive vocabulary size, having a secondary caregiver and reported health problems were significant predictors, but only when evaluated in separate models. The reason for this is that having a secondary caregiver and reported health problems were highly associated with the rural community, and not so much with the urban community. Moreover, maternal education levels were generally lower in the rural area than in the urban area. Therefore, location appeared to be the best predictor of expressive and receptive vocabulary size. In the remainder, we will discuss these findings in more detail.

Girls produced and comprehended more words than boys, but this effect was relatively small. This is consistent with findings from other studies in which gender does not tend to have a large effect on vocabulary size (e.g., JacksonMaldonado et al., 2013 [5]).

SES, as measured through maternal education level, was positively related to expressive vocabulary size, but not to receptive vocabulary size. Specifically, children of mothers who received secondary education or higher developed a larger expressive vocabulary than children of mothers who received only primary education or no education at all. This effect of maternal education level on expressive vocabulary size is consistent with other studies that investigated the effect of SES on vocabulary development [1, 4, 5, 15, 27]. Highly educated mothers tend to talk more to their children, use more positive feedback, and accompany their speech more often with gestures that may help the children to identify the intended referents for words [27, 35]. It is unclear why maternal education had no significant effect on receptive vocabulary size, but this may be explained by differences 


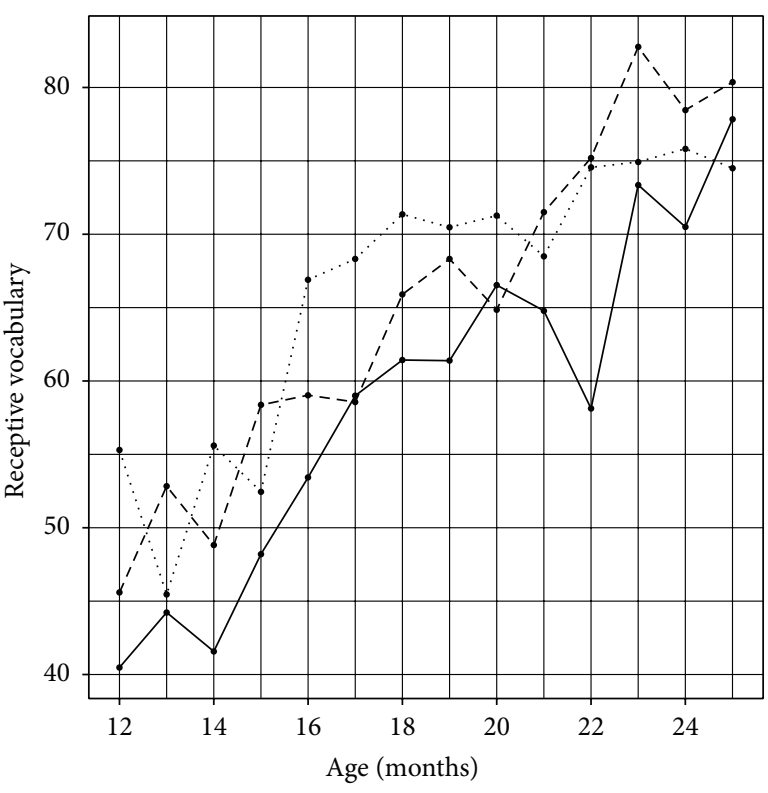

Secondary

- None

..... Sibling

--- Adult

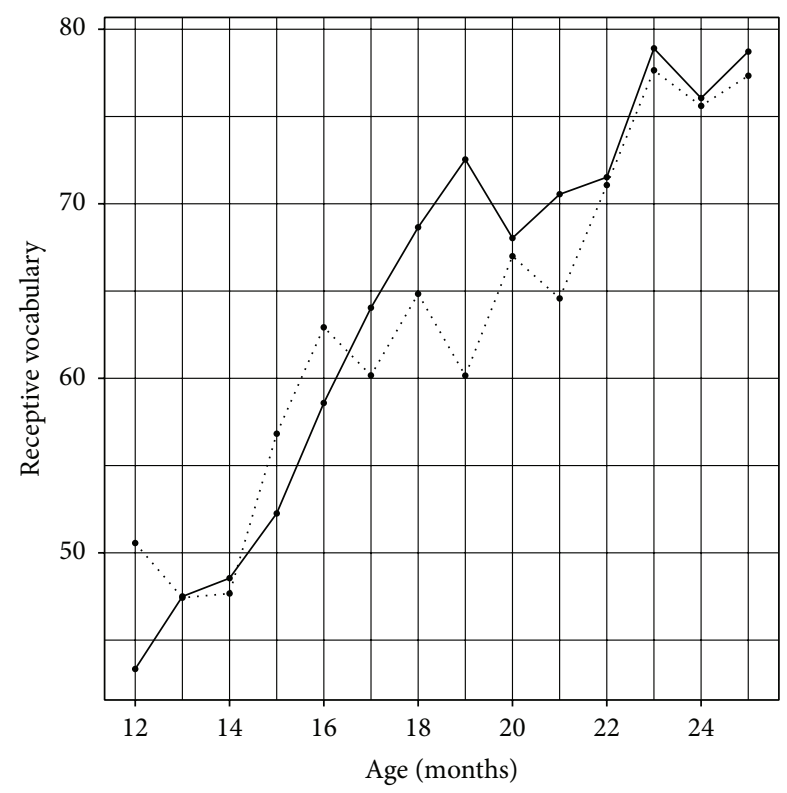

Health problems - No

(a)

(b)

FIGURE 4: The average scores on receptive vocabulary per month for the three types of secondary caregivers evaluated (a) and for children with and without reported health problems (b).

between the rural and urban communities, as we will further discuss below.

In addition to maternal education level, location was a strong predictor of expressive vocabulary size. Children from the urban community developed substantially larger expressive vocabularies than children from the rural community. Given the generally higher levels of SES in urban communities through higher income and higher education [25], the higher levels of expressive vocabulary may be attributed to an added effect of SES. We have noticed in a number of studies that urban caregivers socialize more with their children than rural caregivers. For instance, we have observed substantial differences between the communities regarding the amounts and types of child-directed speech and gestures $[10,12]$, as well as the way in which children engage with their social environment [11]. In particular, we have observed that the linguistic input urban children receive is richer in terms of speech and gesture and that these children engage in more episodes of joint attention than rural children. As each of these aspects has been related to children's vocabulary growth $[4,27,28,36,37]$, it is conceivable that these cultural differences can explain the differences in vocabulary development observed in this study. This would also be in line with related observations that children in various non-Western rural populations receive less linguistic input, such as fewer declaratives or questions, than in most Western communities [29, 38, 39], as well as those from various non-Western urban communities [40].
Contrary to the findings for word production, children comprehended significantly less words in the urban community than children in the rural community, and this effect appeared to be more substantial for the younger age groups (cf. Figure 4). Differences in SES between the two communities also may explain this finding. For instance, Jackson-Maldonado and colleagues [5] suggested that low SES mothers may overestimate their child's level of receptive vocabulary, especially early during development. Such an explanation is in place, because studies with more direct measures of comprehension have shown that children from a low SES background tend to score lower on comprehension tasks than children from a high SES background [4]. It is unclear why low educated mothers overestimate their children's comprehension, but it is conceivable that they experienced some difficulties with understanding the instructions or that they found it hard to judge what word their child could comprehend. More direct measures of language comprehension, such as the computerized comprehension task [41] orfor slightly older children-the Peabody picture vocabulary test [42] would arguably yield more reliable estimates of word comprehension.

Another reason why rural mothers may overestimate their child's receptive vocabulary size is that they often leave them in the care of someone else. Since many nonWestern communities, such as in Mozambique, tend to have multiple caregiving systems, including sibling caregiving [25, $26,33]$, we expect that this influences children's language 
development. Our analyses that include having a secondary caregiver as predictor for vocabulary development suggest that this is the case.

We observed that children who were reported to have a sibling caregiver developed their expressive vocabulary slower than those who were reported to have either no secondary caregiver or an adult caregiver. While this effect is small, it is in line with findings from Harkness who showed that in rural Kenya children who socialized more with siblings had a smaller expressive vocabulary than those who socialized more with their mothers [33].

In contrast, we found that children with a sibling or an adult as secondary caregiver had higher scores on receptive vocabulary. This suggests that having multiple caregivers has a beneficial effect on children's language comprehension, irrespective of whether these are sibling caregivers or adult caregivers. However, as mentioned, it may also indicate that mothers who regularly leave their child in the care of others might overestimate their child's language comprehension more than mothers who do not.

Another important factor that influences children's language development is their health [32]. Our findings confirm that health problems slow down expressive and receptive vocabulary growth. Mozambique faces several major public health problems, including endemic malaria, a high HIV prevalence, and many other infectious diseases. The site where the children were recruited appears to be especially affected by these problems [43]. This is also reflected in the demographic information obtained from our respondents, where more than $50 \%$ of rural caregivers reported one or more health problems during the children's development compared to $14 \%$ of urban caregivers (see Table 1). The CDI adaptation could be a useful tool to investigate what types of health issues affect language outcomes in developing countries such as Mozambique.

There are two limitations with our approach that we would like to discuss here. First, the CDI adaptation presented in this paper was developed using the short version of the US English CDI [9] rather than using long versions of the same languages as is common $[5,19]$ or by using frequencies of word lists obtained by interviewing mothers [21]. While such approaches would undoubtedly yield word lists that better reflect children's vocabulary, such methods are time consuming and expensive, especially when longer CDI versions or frequency lists are not available as in the case of Mozambique. Adapting the English version by translating culturally appropriate words and by replacing culturally inappropriate words is then a suitable and relatively costeffective alternative [8]. However, the use of such adaptations should be treated with care.

Second, as discussed above, the observed differences in expressive vocabulary size between the bilingual Portuguese and Ronga speaking urban community and the monolingual Changana speaking rural community can be explained based on differences in SES, culture, and reported health problems. However, it is conceivable that the parental checklist used in both communities has a slight bias for words acquired earlier in the urban community compared to in the rural community. We have kept this in mind while adapting the
CDI and we have tried to counterbalance items that would likely trigger a response in only one community. Our item-byitem comparison of the responses to expressive vocabulary items revealed that there were a few items with either a floor or ceiling effect. Consequently, the Mozambican CDI needs more fine-tuning before it can be used for clinical purposes, for instance, by replacing the few items that always had a floor or ceiling effect with items that at least a decent proportion of children would be able to express and improving the translation of other few items so that they are better in line with the way children express these items. One should also consider whether or not to develop separate CDIs for the two learning environments.

\section{Conclusion}

The adapted CDI short form has proven to be a useful instrument to assess vocabulary development among Mozambican children between 12 and 25 months of age. Although the instrument was translated into three languages (Changana, Ronga, and Portuguese), the conceptual items were the same. Moreover, the effort to distinguish between Changana and Ronga may not have been necessary, as more urban people are identified as Changana speakers than Ronga speakers and both languages are mutually intelligible, so the CDI lists may be merged. Languages from the whole Tsonga family (Changana, Ronga, Tonga, and Tswa) are spoken in parts of South Africa, Swaziland, Zimbabwe, and the Inhambane province of Mozambique [13]. It would be interesting to see how our instrument works in other regions where languages are spoken that belong to the same language family.

It has been suggested that, in order to tackle poverty, it is important to improve early child care, not only by improving nutrition and health care, but also by improving the cognitive and linguistic development of children at the early stages by providing culturally targeted maternal education on child development [44]. In order to develop effective intervention programs to improve children's language development, it is crucial to understand what factors may influence parental behavior. The present study has demonstrated that SES as measured through maternal education, reported health problems, and whether or not children have a secondary caregiver are factors that influence vocabulary development. Moreover, these factors appear to be more problematically abundant in rural areas than in urban areas. A wider utility of CDI adaptations in sub-Saharan Africa-as well as in many other developing countries-could help to improve our understanding of what (other) demographic and health factors may affect vocabulary development.

The current CDI can serve as a starting point for other CDI adaptations in related Bantu languages spoken in related cultural communities within Southern Africa. Adapting CDIs for related African languages has proven to be successful in the past $[7,18]$. There are many different Bantu languages spoken in sub-Saharan Africa-in Mozambique alone 23 Bantu languages are spoken [14], most in rural areas-and relatively few resources exist to develop proper instruments to assess the vocabulary development of young children. Since 
TABle 4: The Mozambican CDI word list.

\begin{tabular}{|c|c|c|c|}
\hline English & Portuguese & Changana & Ronga \\
\hline Dada & Dada & Taa-taa & Taa-taa \\
\hline Bird & Ave & Nyanyana & Nyanyana \\
\hline Dog & Cão & Mdzáná & Mdzáná \\
\hline Goat & Gabrito & Mbútí & Mbútí \\
\hline Chicken & Galinha & Húkú & Húkú \\
\hline Ox & Bois & Homu & Homu \\
\hline Rat & Rato & Kondlo & Khondlo \\
\hline Car & Carro & Mohva & Mohva \\
\hline Carry-cloth & Neneca & Beleca & Beleca \\
\hline Ball & Bola & Bóla & Bóla \\
\hline Water jug & Bidon de agua & Xigubugubu & Xigubugubu \\
\hline Doll & Boneca & Xibonécani & Xibonécani \\
\hline Bread & Pão & Pawa & Pawu \\
\hline Sweets & Doces & Docane & Docane \\
\hline Rice & Arroz & Mpunga & Mpunga \\
\hline Biscuit/cookie & Biscuito & Xi bubutela/buláti/Bulaxa & $\begin{array}{l}\mathrm{Xi} \\
\text { bubutela/buláti/bulaxa }\end{array}$ \\
\hline Tea & Cha & Txána & Txána \\
\hline Polenta-like food & Xima & Uswa & Uswha \\
\hline Cap/hat & Chapéu & Xidhloko & Xilembe \\
\hline Trousers & Calças & Bulúkú & Bulúkú \\
\hline Shoe & Sapato & Xifamba & Xifambu \\
\hline Shirt & Camisa & Hémbe & Hémbe \\
\hline Eye & Olho & Tíhlo/mahlu & Tíhlo/mahlu \\
\hline Head & Cabeza & Nhloko & Nhloko \\
\hline Leg & Perna & Nengue & Nengue \\
\hline Nose & Nariz & Nhómpfú & Nhómpfú \\
\hline Tooth & Dente & Tínyó & Tínyó \\
\hline Chair & Cadeira & Xitsámú/xitulu & Xithrámú/xistulu \\
\hline Sofa/couch & Sofa & Stofada/sofa & Stofada/sofa \\
\hline Toilet & Casa de banho & Xikóti & Xikóti \\
\hline Table & Mesa & Méza/tafula & Méza/tafula \\
\hline Cell phone & Cel & Celula fone & Fone \\
\hline Blanket & Manta & Vóló & Gúmana/volo \\
\hline Bottle & Garafa & Bolhela & Bolhela \\
\hline Cup/glass & Copo & Copo/biquiri & Copo/biquiri/xikire \\
\hline Plate & Prato & Paratu & Paratu \\
\hline Lamp/candle & Vela & Khandlelo/lampu & Khandlelo/lampu \\
\hline Radio & Radio & Radio & Radio \\
\hline Spoon & Colher & Xipúnú & Xipúnú \\
\hline Stick & Bastão & Nhóngá & Nhóngá \\
\hline Home & Em casa & Káyá & Káyá \\
\hline Sun & Sol & Mumú & Mumú \\
\hline Outside & Fora & Handle & Handle \\
\hline Tree & Árvore & Nsínya & Nsínya \\
\hline Rain & Chuva & Mpfúlá & Mpfúlá \\
\hline Dirt/soil & Areia & Misává & Misává \\
\hline Water & Agua & Mati & Mati \\
\hline Friend & Amigo & Munghanu & Munghanu \\
\hline
\end{tabular}


TABLE 4: Continued.

\begin{tabular}{|c|c|c|c|}
\hline English & Portuguese & Changana & Ronga \\
\hline Girl (teenage) & Menina & N'hwanyana & N'hwanyana \\
\hline Grandmother & Vovo & Kokwana/vovo & Kokwana/vovo \\
\hline Mother & Mamai/mãe & Mamana & Mamana \\
\hline to bathe & Tomar banho & $\mathrm{Ku}$-thlamba & $\mathrm{Ku}$-thlamba \\
\hline Leave it & Deixe & Tsika & Tsika \\
\hline Welcome & Bem vindo & Hóyohóyo & Hóyohóyo \\
\hline See you tomorrow & Até a manha & Tapuxani & Tapuxani/até mudzuku \\
\hline Now! & Agora! & Svósvi & Svósvi \\
\hline Wait & Espera & Nyímá & Nyímá \\
\hline Go! & Vai! & Famba! & Famba! \\
\hline Eat! & Come! & $\mathrm{Ku}$-dla/dlana! & $\mathrm{Ku}$-dla/dlana! \\
\hline To finish & Acabar & Ku -héta & Ku -héta/ku -héla \\
\hline To bring & Trazer/traga & Ku -vúyísá & Ku -búyísá \\
\hline To fall & Cair & $\mathrm{Ku}-\mathrm{wa}$ & $\mathrm{Ku}-\mathrm{wa}$ \\
\hline To kick & Pontape & $\mathrm{Ku}$-mutapí & $\mathrm{Ku}$-mutapí \\
\hline To hug & Abraçar & $\mathrm{Ku}$-xinga & Ku -xíngárhéla \\
\hline To push & Empurrar & $\mathrm{Ku}$-chova & $\mathrm{Ku}$-chova \\
\hline To sing & Cantar & $\mathrm{Ku}$-nyimbelela & Ku nyimbelela \\
\hline Night & Noite & Wusíkú & Wusíkú \\
\hline Today & Hoje & Namúnlha & Namúnlha \\
\hline All gone & Acabou & Hi mbetile & Hi mbelile \\
\hline Big & Grande & -Kulu & -Kulu \\
\hline Broken & Quebrado & -Tshova & -Trhova/'-trhoveka \\
\hline Shiny & Brilhante & -Phatima & -Phatima \\
\hline Fast & Rapido & -Kahlula & -Kahlula \\
\hline Hunger & Fome & Ndlala & Ndlala \\
\hline Pretty & Beleza & -Xonga & -Xonga \\
\hline Hard & Duro & -Dziva & -Tíyá/-tíyélá \\
\hline I & $\mathrm{Eu}$ & Mina & Mine \\
\hline You & $\mathrm{Tu}$ & Wena & Wene \\
\hline How & Como & Ndjani & Yíní \\
\hline Who & Quem & -Mání & -Mání \\
\hline Long/far away & Longe & Kule & Kule \\
\hline Inside & Dentro & Ndzeni & Ndzeni \\
\hline Other & Outro & -Nwána & -N’wána \\
\hline Many/much & Muito & -Nyingi & -Nyingi \\
\hline Wheelbarrow & Carrinho de mão & Escarinyana & Escarinyana \\
\hline Meat & Carne & Nyama & Nyama \\
\hline Ear & Orelha & Ndlevé & Ndlevé \\
\hline Arm & Braço & Vókó & Vókó \\
\hline Bed & Cama & Mubéde & Mubéde \\
\hline Wind & Vento & Móyá & Móyá \\
\hline Cloud & Nuvem & Refu & Refu \\
\hline Heaven & Céu & Tilo & Tilo \\
\hline Goodbye & Adeus & Salani & Hambanini! \\
\hline Thank you & Obrigado & Khanímámbu!/ni khensile/inkomu/ni bongile & $\begin{array}{l}\text { Khanímámbu!/ni } \\
\text { khensile/inkomu/ni } \\
\text { bongile }\end{array}$ \\
\hline
\end{tabular}


TABLE 4: Continued.

\begin{tabular}{llll}
\hline English & Portuguese & Changana & Ronga \\
\hline To chase & Perseguir & $\mathrm{Ku}$-tshatsha & $\mathrm{Ku}$-tshatcha \\
To listen & Escutar & $\mathrm{Ku}$-yingisa - yingisa \\
To drink & Beber & $\mathrm{Ku}$-phusa & $\mathrm{Ku}-\mathrm{nwá}$ \\
To think & Pensar & $\mathrm{Ku}$-pimisa & $\mathrm{Ku}-\mathrm{pimisa} / \mathrm{ku}$ \\
Strong & Forte & -Ntamu & yanakanya \\
Hot & Quente & - Hísá & -Ntamu \\
Small & Pequeno & - Tsóngó & -Hísá \\
After & Depois/atras & Ndzaku & -Tsóngó \\
Them & Eles & Vona & Ntrhákú \\
This & Este/esta/isto & Lexi & Wone \\
Us & Nós & Hina & Lexi \\
Where & Onde & Kwíni & Hine \\
Below/under & Debaixo & Hánsí & Kwíní \\
If/when & Se/quando/enquanto & Loko & Hánsí \\
\hline
\end{tabular}

Notes. A dash before the Changana and Ronga entries indicates these entries are suffixes. The prefix "Ku" indicates the infinitives of verbs. Acute accents are used to indicate high tones in the vowels.

many of these language communities share similar cultural traditions and environments, direct translations between these communities may be cost-effective ways to develop tools that can be used to assess vocabulary development.

\section{Appendix}

See Table 4.

\section{Conflict of Interests}

The authors declare that there is no conflict of interests regarding the publication of this paper.

\section{Acknowledgments}

This research was funded by the Netherlands Organization for Scientific Research (NWO) with a VIDI grant (no. 27670-018) awarded to Paul Vogt. The authors thank Martijn Goudbeek for his advice on the statistical analyses and comments on an earlier version of this paper. Many thanks are due to Wona Sanana, Associação Communitário Ambiente da Mafalala, and the local research assistants for their support in Mozambique. Finally, the authors' gratitude goes to all participants involved in their study.

\section{References}

[1] L. Fenson, P. S. Dale, J. S. Reznick et al., The MacArthur Communicative Development Inventories: User's Guide and Technical Manual, Singular Publishing Group, San Diego, Calif, USA, 1993.

[2] M. H. Bornstein, L. R. Cote, S. Maital et al., "Cross-linguistic analysis of vocabulary in young children: Spanish, Dutch,
French, Hebrew, Italian, Korean, and American English," Child Development, vol. 75, no. 4, pp. 1115-1139, 2004.

[3] M. C. Caselli, E. Bates, P. Casadio et al., "A cross-linguistic study of early lexical development," Cognitive Development, vol. 10, no. 2, pp. 159-199, 1995.

[4] A. Fernald, V. A. Marchman, and A. Weisleder, "SES differences in language processing skill and vocabulary are evident at 18 months," Developmental Science, vol. 16, no. 2, pp. 234-248, 2013.

[5] D. Jackson-Maldonado, V. Marchman, and L. Fernald, "Shortform versions of the Spanish MacArthur-Bates communicative development inventories," Applied Psycholinguistics, vol. 34, no. 4, pp. 837-868, 2013.

[6] P. S. Dale and M. Penford, "Adaptations of the MacArthur-bates CDI into non-U.S. English languages," Unpublished Survey, 2011.

[7] K. Alcock and N. Alibhai, "Language development in SubSaharan Africa," in Neuropsychology of Children in Africa, pp. 155-180, Springer, Berlin, Germany, 2013.

[8] J. B. Childers, J. Vaughan, and D. A. Burquest, "Joint attention and word learning in Ngas-speaking toddlers in Nigeria," Journal of Child Language, vol. 34, no. 2, pp. 199-225, 2007.

[9] L. Fenson, S. Pethick, C. Renda, J. L. Cox, P. S. Dale, and J. S. Reznick, "Short-form versions of the MacArthur communicative development inventories," Applied Psycholinguistics, vol. 21, no. 1, pp. 95-116, 2000.

[10] P. Vogt and J. D. Mastin, "Rural and urban differences in language socialization and early vocabulary development in Mozambique," in Proceedings of the 35th Annual Conference of the Cognitive Science Society (CogSci '13), M. Knauff, M. Pauen, N. Sebanz, and I. Wachsmuth, Eds., pp. 3787-3792, Cognitive Science Society, Austin, Tex, USA, July-August 2013.

[11] J. D. Mastin and P. Vogt, "Infant engagement and early vocabulary development: a naturalistic observation study of Mozambican infants from 1;1 to 2;1," Journal of Child Language, 30 pages, 2015. 
[12] P. Vogt, J. D. Mastin, and D. M. A. Schots, "Communicative intentions of child-directed speech in three different learning environments: observations from the Netherlands, and rural and urban Mozambique," First Language, vol. 35, no. 4-5, pp. 341-358, 2015.

[13] M. Da Conceição, "A brief look at the sociolinguistics of Ronga and other languages spoken in Mozambique," University of Washington Working Papers in Linguistics 16, University of Washington, 1999.

[14] M. P. Lewis, Ethnologue: Languages of the World, SIL International, 2009.

[15] T. Tardif, P. Fletcher, W. Liang, and N. Kaciroti, "Early vocabulary development in Mandarin (Putonghua) and Cantonese," Journal of Child Language, vol. 36, no. 5, pp. 1115-1144, 2009.

[16] G. Szagun, B. Stumper, and S. A. Schramm, FRAKIS: Fragebogen zur Frühkindlichen Sprachentwicklung (FRAKIS) und FRAKISK (Kurzform), Pearson, 2009.

[17] M. Eriksson, M. Westerlund, and E. Berglund, "A screening version of the Swedish communicative development inventories designed for use with 18-month-old children," Journal of Speech, Language, and Hearing Research, vol. 45, no. 5, pp. 948-960, 2002.

[18] E. L. Prado, K. J. Alcock, M. T. Ullman, J. Phuka, B. Yakes, and M. Arimond, "Assessing child development in the context of nutriation trials in developing countries: principles of test selection, adaptation and evaluation," in Proceedings of the Lipid-Based Nutrient Supplements Research Network Meeting, Washington, DC, USA, 2011.

[19] K. J. Alcock, K. Rimba, P. Holding, P. Kitsao-Wekulo, A. Abubakar, and C. R. J. C. Newton, "Developmental inventories using illiterate parents as informants: Communicative Development Inventory (CDI) adaptation for two Kenyan languages," Journal of Child Language, vol. 42, no. 4, pp. 763-785, 2015.

[20] F. van de Vijver, "Meta-analysis of cross-cultural comparisons of cognitive test performance," Journal of Cross-Cultural Psychology, vol. 28, no. 6, pp. 678-709, 1997.

[21] J. D. Hamadani, H. Baker-Henningham, F. Tofail, F. Mehrin, S. N. Huda, and S. M. Grantham-McGregor, "Validity and reliability of mothers' reports of language development in 1year-old children in a large-scale survey in Bangladesh," Food \& Nutrition Bulletin, vol. 31, supplement 2, pp. S198-S206, 2010.

[22] E. Bates and B. MacWhinney, "Mechanisms of language acquisition," in Mechanisms of Language Acquisition, B. MacWhinney, Ed., pp. 157-193, Erlbaum, Hillsdale, NJ, USA, 1987.

[23] D. A. Junker and I. J. Stockman, "Expressive vocabulary of German-English bilingual toddlers," American Journal of Speech-Language Pathology, vol. 11, no. 4, pp. 381-394, 2002.

[24] B. Z. Pearson, S. C. Fernández, and D. K. Oller, "Lexical development in bilingual infants and toddlers: comparison to monolingual norms," Language Learning, vol. 43, no. 1, pp. 93120, 1993.

[25] P. M. Greenfield, "Linking social change and developmental change: shifting pathways of human development," Developmental Psychology, vol. 45, no. 2, pp. 401-418, 2009.

[26] H. Keller, "Autonomy and relatedness revisited: cultural manifestations of universal human needs," Child Development Perspectives, vol. 6, no. 1, pp. 12-18, 2012.

[27] B. Hart and T. R. Risley, Meaningful Differences in the Everyday Experience of Young American Children, Paul H Brookes Publishing, 1995.
[28] E. Hoff, “The specificity of environmental influence: socioeconomic status affects early vocabulary development via maternal speech," Child Development, vol. 74, no. 5, pp. 1368-1378, 2003.

[29] R. LeVine, S. Dixon, S. LeVine et al., Child care and culture: Lessons from Africa, Cambridge University Press, Cambridge, UK, 1996.

[30] L. Fenson, E. Bates, P. Dale, V. Marchman, J. Reznick, and D. Thal, MacArthur-Bates Communicative Development Inventories, Paul H. Brookes Publishing Company, Baltimore, Md, USA, 2nd edition, 2007.

[31] E. Bates, D. Thal, D. Trauner et al., "From first words to grammar in children with focal brain injury," Developmental Neuropsychology, vol. 13, no. 3, pp. 275-343, 1997.

[32] S. P. Walker, T. D. Wachs, J. M. Gardner et al., "Child development: risk factors for adverse outcomes in developing countries," The Lancet, vol. 369, no. 9556, pp. 145-157, 2007.

[33] S. Harkness, "spects of social environment and first language acquisition in rural Africa," in Talking to Children: Language Input and Acquisition, pp. 309-316, 1977.

[34] B. Sitoe, N. Mahumana, and P. Langa, Dicionário RongaPortuguês, Centre of Research and Promotion of Traditional Medicine (CIPROMETRA), Maputo, Mozambique, 2008.

[35] M. L. Rowe, Ş. Özçalişkan, and S. Goldin-Meadow, "Learning words by hand: Gesture's role in predicting vocabulary development," First language, vol. 28, no. 2, pp. 182-199, 2008.

[36] M. L. Rowe and S. Goldin-Meadow, "Differences in early gesture explain SES disparities in child vocabulary size at school entry," Science, vol. 323, no. 5916, pp. 951-953, 2009.

[37] M. Tomasello and J. Todd, "Joint attention and lexical acquisition style," First Language, vol. 4, no. 12, pp. 197-211, 1983.

[38] E. Lieven, "Crosslinguistic and crosscultural aspects of language addressed to children," in Input and Interaction in Language Acquisition, C. Gallaway and B. J. Richards, Eds., Cambridge University Press, Cambridge, UK, 1994.

[39] L. A. Shneidman, M. E. Arroyo, S. C. Levine, and S. GoldinMeadow, "What counts as effective input for word learning?" Journal of Child Language, vol. 40, no. 3, pp. 672-686, 2013.

[40] L. Kirk, "Cross-cultural measurement of maternal behavior in mother-child teaching interaction," Quality \& Quantity, vol. 10, no. 2, pp. 127-143, 1976.

[41] M. Friend and M. Keplinger, "Reliability and validity of the Computerized Comprehension Task (CCT): data from American English and Mexican Spanish infants," Journal of Child Language, vol. 35, no. 1, pp. 77-98, 2008.

[42] L. Dunn, L. Dunn, S. Bulheller, and H. Häcker, Peabody Picture Vocabulary Test, American Guidance Service, Circle Pines, Minn, USA, 1965.

[43] D. H. S. Moçambique, "Inquérito demográfico e de saúde," Tech. Rep., Instituto Nacional deEstatística, Ministério de Saúde, 2013.

[44] S. Grantham-McGregor, Y. B. Cheung, S. Cueto, P. Glewwe, L. Richter, and B. Strupp, "Developmental potential in the first 5 years for children in developing countries," The Lancet, vol. 369, no. 9555 , pp. $60-70,2007$. 

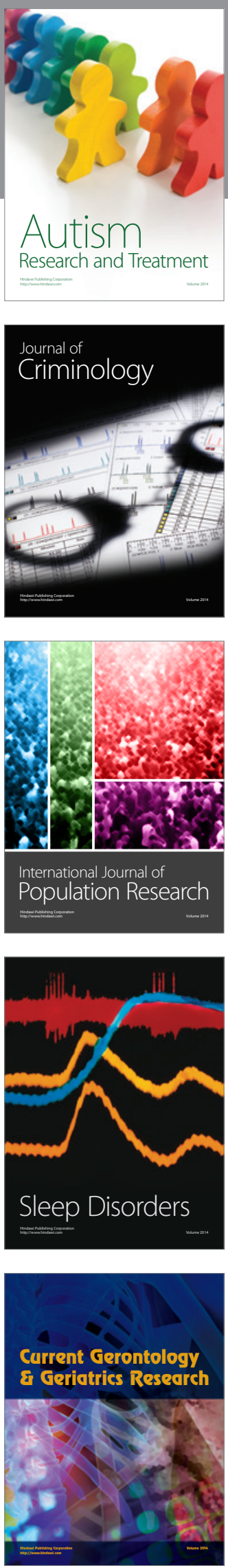
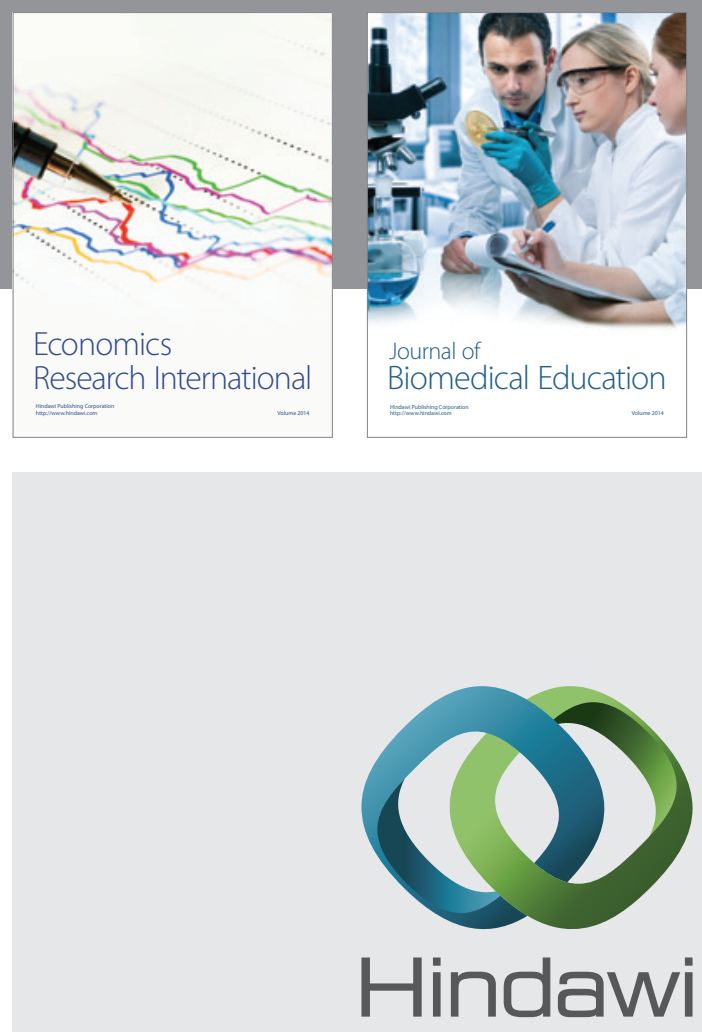

Submit your manuscripts at

http://www.hindawi.com
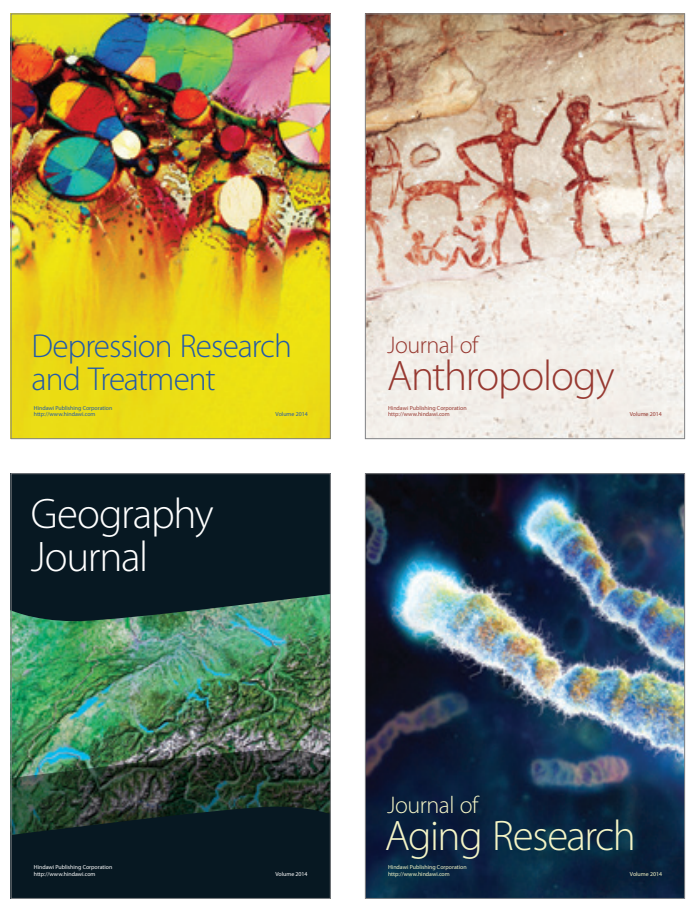
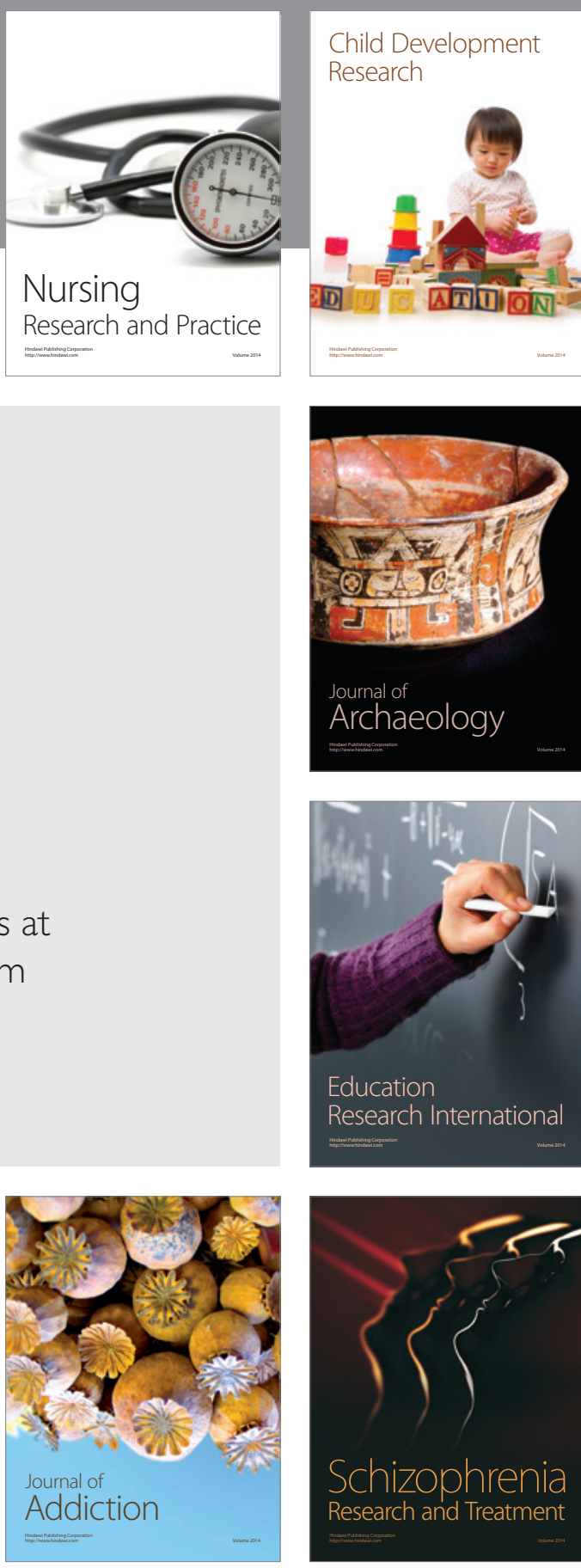

(D)
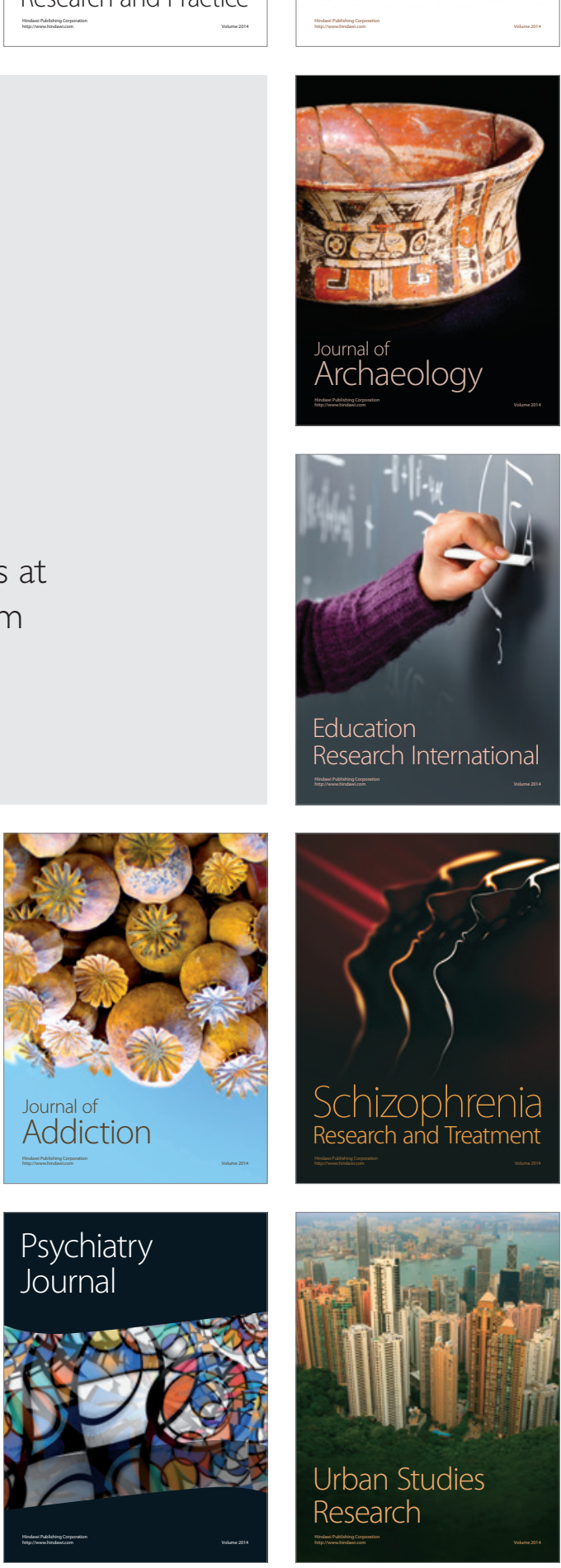